\title{
ARQUITETURA DA PAISAGEM DA CIDADE E A IMPORTÂNCIA DA SISTEMATIZAÇÃO DA ANÁLISE DO PROBLEMA PROJETUAL
}

\author{
ARCHITECTURE OF THE LANDSCAPE OF THE CITY AND THE IMPORTANCE OF THE \\ SYSTEMATIZATION OF THE ANALYSIS OF PROJECT PROBLEM
}

\begin{abstract}
SANTOS, Rodrigo Gonçalves dos
Arquiteto; MSc.; Professor do Curso de Design do CEFET/SC; Endereço: Serv. Hilário Manoel da Silva, 137, Cachoeira do Bom Jesus, Florianópolis, SC, CEP 88056-345. E-mail: rodgonca@cefetsc.edu.br
\end{abstract}

SANTIAGO, Alina Gonçalves

Arquiteta; Dra.; Professora do Departamento de Arquitetura da UFSC. e-mail: alina@arq.ufsc.br

\section{RESUMO}

Com este artigo pretende-se levantar os conceitos próprios da atividade da Arquitetura Paisagística encarando-a como disciplina projetual e associando-a ao Design Ambiental, necessitando, assim, de linhas metodológicas específicas para apresentação de soluções coerentes aos problemas paisagísticos. Sob esta ótica, reflexões sobre o uso da vegetação no projeto dos espaços exteriores são apresentadas apontando-se uma etapa de sistematização da análise do problema de projeto, dentro da abordagem da concepção de uma metodologia projetual em arquitetura paisagística. Também foram analisadas oito vias de circulação da área central de Florianópolis, Santa Catarina, Brasil, exemplificando uma etapa de sistematização da análise do problema de projeto.

Palavras-chave: Paisagismo, metodologia projetual, desenho urbano.

\begin{abstract}
Through this paper there was an attempt to draw out the intrinsic concepts within the activity of landscape architecture, whereas it is viewed as a project discipline which, therefore, needs methodological strategies specific to the creation of coherent solutions for landscape problems. From this point of view, reflections were made on the use of vegetation in the design of exterior spaces. At the end of this paper, the stage of analysis and comprehension of the project problem came into focus. This was approached as the conception of a project methodology in landscape architecture. The field study analysed eight streets in downtown Florianópolis, Santa Catarina, Brazil, in an attempt to understand the insertion of urban vegetation in the open spaces of the transportation network of this area.
\end{abstract}

Key words: Landscape architecture, project methodology, urban design.

\section{Arquitetura da paisagem como disciplina projetual}

A Arquitetura Paisagística foi institucionalizada, no último quartel do século XIX, buscando tratar a paisagem de forma prática como fazem os arquitetos, ou seja, analisar os problemas e apresentar soluções através de desenhos. Neste primeiro momento, a questão ambiental sempre era a pauta das preocupações, o que se perderia no decorrer da consolidação da atuação dos profissionais da arquitetura da paisagem, mas que seria retomada novamente somente no século XX, mais precisamente na década de 70.

A concepção do jardim foi um dos primeiros campos de intervenção da Arquitetura Paisagística, sendo que o jardim representa a forma mais sintética e representativa do espaço exterior construída pelo homem. Após a Revolução Industrial, com o crescimento da cidade, surgem problemas na morfologia da própria cidade (deficiências no saneamento básico, traçado de ruas que não correspondiam às necessidades emergentes da nova sociedade, entre outros) e com ela maneiras ineficientes de se distribuir os espaços verdes na cidade. $O$ jardim cede seu lugar ao pequeno espaço verde e ao parque público urbano, e este, ao sistema de parques e aos corredores de 
vegetação, quando se verificou que o parque não era por si só suficiente para cumprir as funções de uso e de proteção necessárias à vida do homem (MAGALHÃES, 2001). A atividade da Arquitetura Paisagística é tratada por Magalhães (2001, p.65) da seguinte forma:

A Arquitetura Paisagística molda a paisagem que constitui o objeto de sua intervenção, ou seja, dá forma à intervenção do homem num espaço onde interagem as componentes ecológicas e culturais, entendendo este espaço como um fenômeno arquitetônico. Trata-se, portanto, do mesmo modo que a Arquitetura, de uma disciplina projetual.

\section{Tipologias do espaço exterior}

Conceito de tipologia aplicado à paisagem urbana nos remete à uma relação entre o espaço edificado e o não-edificado, a qual define o tecido urbano. Esta situação se especifica ainda mais quando a relação também se estende entre volumes e superfícies, sendo estas revestidas por vegetação ou materiais inertes e aqueles formados por massas de vegetação ou elementos edificados (MAGALHÃES, 2001).

Ao sistematizarmos tipologias utilizadas no espaço exterior usando como material formal a vegetação criamos um conjunto simples de orientações que possam constituir uma ferramenta de projeto. Podemos, então, considerar as seguintes tipologias (MAGALHÃES, 2001):

1. Espaço fechado: Ocupado por volumes de vegetação densa, sendo ao nível da copa (matas, por exemplo) ou ao nível mais baixo (maciços de arbustos densos). Dentro desta tipologia podemos ainda considerar sub-tipologias:

a) Espaço fechado sem borda: troncos altos formam ambiente relativamente fechado, onde, no entanto, pode-se ter alguma sensação de abertura ao nível destes troncos altos (plano vertical).

b) Espaço fechado com borda: representado pelos maciços de arbustos com dimensão onde o acesso é dificultado, ou seja, onde há uma sensação de envolvimento pela vegetação sem qualquer abertura para o exterior.

2. Espaço aberto: Espaço com dimensão considerável com pouca ou nenhuma vegetação, como um gramado ou prado, onde existe uma sensação de abertura embora se esteja contido entre limites mais ou menos permeáveis, situados à uma distância.

3. Espaço ilimitado: Aqui não se sentem limites por causa da grande extensão de céu visível. Neste espaço não se vêem os limites, embora estes se situem à grande distância.

4. Espaço pontuado: Espaço aberto com pontuações formadas por árvores ou arbustos isolados.

5. Espaço compartimentado: Espaço aberto compartimentado por planos verticais. Os planos verticais são formados por alinhamentos de árvores ou arbustos, sebes, etc .

\section{A presença da vegetação no sistema viário: entendendo a importância das espécies vegetais nas vias da cidade}

Traçados geométricos são constantes no que se refere à configuração do sistema viário, fato o qual se justifica pelo legado de nossa colonização. A característica mais fundamental de um sistema viário é a função de comunicar lugares através de vias hierarquizadas. Então, pode-se considerar como sistema viário o conjunto de vias públicas que estabelecem comunicações entre os diferentes lugares da cidade. Estas vias podem ser aquelas destinadas ao trânsito de veículos (rodovias, vias parques, ruas, avenidas, travessas, boulevards, alamedas, etc.) e também ao trânsito de pedestres (passeios, calçadões, etc.), bem como ciclovias. 
É através do sistema viário que nos deslocamos pela cidade, bem como somos vistos e vemos a dinâmica da cidade. Em decorrência disto, é nas ruas que a vegetação desempenha papel importante como elemento do desenho urbano, dando um aspecto estético imprescindível à cidade.

Spirn (1995) considera as árvores das ruas como o maior investimento em vegetação da maioria das cidades. As árvores influenciam o clima e a aparência dos locais de vivência e trabalho das pessoas. A autora constata, ainda, que o passeio foi durante muito tempo uma recreação urbana apreciada e as ruas margeadas por árvores eram contribuintes para este propósito.

Em relação ao planejamento do plantio das espécies vegetais e seus agrupamentos deve-se diferenciar dois fatores importantes: (1) o plantio linear ou geométrico, o qual enfatiza uma interferência antrópica na paisagem; e (2) o plantio livre onde se busca uma semelhança a conjuntos vegetais existentes na natureza. Devido à distribuição linear das ruas e avenidas, no sistema viário a tendência é o plantio geométrico. A partir do momento que a configuração das vias de um sistema viário se torna mais complexo - como por exemplo avenidas com mais de uma pista separadas por canteiros centrais com dimensões consideráveis, ou vias parques com retornos e trevos com grandes proporções - o plantio pode ser mais livre, o que pode caracterizar o conjunto de várias vias parques como um parque.

\section{O projeto dos espaços livres no sistema viário utilizando a vegetação}

Uma via urbana com um tratamento adequado com a vegetação tem como futuro o fechamento dos planos da base, verticais e do teto. Desta forma, esta via se torna um volume tridimensional limitado pelas relações que tais planos proporcionam. Estas relações são resultantes do gradual fechamento dos planos já citados - devido ao crescimento das espécies vegetais - ou do fechamento já consolidado por espécies adultas - quando estas são plantadas no tamanho adulto ou transplantadas de outras áreas.

As relações mais interessantes, segundo Grey \& Deneke (1978), se dão no fechamento vertical. O fechamento do plano vertical com a vegetação pode gerar o controle visual através da pemeabilidade de visão que se dá devido às diferentes alturas das espécies vegetais. Um objeto pode ser valorizado ou negado pela manipulação do plano vertical e seu fechamento através de contrastes, causando interesses ao observador.

\section{A relação entre arquitetura paisagística e design ambiental fomentando uma metodologia projetual}

Inevitavelmente o arquiteto que atua no campo da Arquitetura Paisagística intervém na paisagem numa grande escala, o que originou uma importante linha de estudos e pesquisas que culminaram em 1969 com o lançamento do livro Design with Nature de lan MacHarg. O livro tornou-se uma referência nas metodologias de planejamento paisagístico urbano até os dias de hoje, originando a prática de sobreposição manual de análises temáticas (mapas temáticos). Os dados apresentados e cruzados pela metodologia explicitada por lan McHarg traziam informações de fatores ambientais e de humanização da paisagem. O principal objetivo do autor era racionalizar a utilização do solo pelas atividades humanas, o que hoje podemos designar por sustentabilidade ecológica.

lan McHarg foi pioneiro ao tentar organizar a tarefa de planejar e projetar a paisagem em um método, o qual foi testado em diversos estudos de casos e consultorias a órgãos de planejamento, assim como em experiências acadêmicas.

Em sua metodologia, McHarg começa realizando um inventário ecológico da área em estudo apresentando fatores considerados indicadores representativos de processos naturais. A 
partir destes fatores, determina a capacidade que possui o ambiente para a implantação das atividades humanas. A capacidade nos é apresentada através de mapas temáticos para cada uso onde era atribuído um valor relativo às atividades humanas, ficando estas definidas entre áreas inaptas para uma atividade específica e áreas aptas, em menor ou maior grau. Um mapa síntese era gerado a partir da integração (sobreposição) dos diversos mapas temáticos. Neste mapa síntese estavam dados referentes à aptidão do solo aos vários tipos de atividade incluindo os usos múltiplos possíveis. Os mapas sínteses dos usos potenciais do solo faziam parte de uma base para a decisão e gestão política, uma vez que se definiam critérios básicos para a ocupação urbana.

Ian MacHarg nos colocava questões acerca da sustentabilidade e conscientização ambiental em meados dos anos 60, e seu texto nos remete a situações atuais, sendo base para outros autores que tratam a questão de ecologia urbana (SPIRN, 1995; HOUGH, 1998; MAGALHÃES, 2001). A grande contribuição de seus estudos é ter colocado o objeto da arquitetura paisagística como problema a ser solucionado através de respostas concatenadas a um diagnóstico claro e específico, ou seja, a paisagem se transforma em alvo de um projeto, de um design. Sob este enfoque, podemos constatar que a atividade da Arquitetura Paisagística acaba sendo expressada por uma prática projetual que transcende as questões estéticas e fundamenta-se em questões formais, estruturais e funcionais, as quais são típicas dos problemas de design.

O Design Ambiental (Environmental Design) se dispõe a tratar problemas projetuais paisagísticos não como desenho, mas sim como um processo orientado por uma metodologia objetivando uma resposta apropriada e inovadora em termos ambientais. Assim, a atividade da Arquitetura Paisagística passa a ser uma atividade integradora de conhecimento e experiência, com uma visão interativa com diversas áreas de conhecimento (FRANCO, 1997, p.11). O design tem como principal característica desenvolver propostas tecnicamente viáveis nas quais está incluída uma parcela de qualidade estético-formal, sendo, conceitualmente, adequado aos trabalhos que envolvem a temática do planejamento da paisagem. Ao atribuir ao design o adjetivo ambiental podemos considerar que estamos projetando o ambiente, decompondo o problema de projeto em várias componentes as quais serão solucionadas adequadamente, sendo que o conjunto destas soluções totalizará uma proposta paisagística com preocupações ambientais.

Desta forma, planejar e projetar paisagens torna-se uma atividade desenvolvida por metodologias específicas de projeto. Ao invés de desenhar soluções em cima de idéias, o arquiteto tem um problema claramente identificado que exige soluções técnicas as quais, dentro de certas limitações, serão fornecidas com criatividade e viabilidade de implantação.

Tendo em vista que o objeto de trabalho do o arquiteto que atua no campo da Arquitetura Paisagística é a paisagem, verificou-se a necessidade de se conceituar tal objeto e suas componentes estruturais. Assim, podemos concluir que a paisagem é tratada pelo arquiteto como um fenômeno arquitetônico sendo composta de um substrato físico onde o homem intervém juntamente com os outros seres vivos. Em conseqüência disto, traçou-se também a definição de espaços livres urbanos sendo estes caracterizados pelo uso público e designados pelos espaços não ocupados pelas edificações no meio urbano (espaços exteriores).

\section{Metodologia projetual em arquitetura paisagística: a vegetação como material formal para o projeto dos espaços exteriores}

No âmbito de uma metodologia projetual, temos as seguintes fases: (1) análise e compreensão do problema, (2) diagnóstico do problema, e (3) proposição da solução do problema. A divisão em fases de uma metodologia projetual não invalida a sua aplicação em várias escalas de intervenção, desde um projeto de pequeno porte até um projeto urbano de grande extensão. 
Ao analisarmos a fundo a temática da vegetação urbana, desde aspectos conceituais até tipologias de espaços exteriores utilizando a vegetação como configurador destes, delineamos uma maneira de analisar os espaços livres e a inserção da vegetação nestes. Já que a atividade da arquitetura paisagística é projetual, pode-se concluir que ao formular uma sistematização da análise do problema de projeto estamos contribuindo para a proposição de soluções mais coerentes, inovadores e criativas.

Sabendo que a vegetação é um dos materiais formais para o projeto dos espaços livres urbanos, podemos situar o que foi apresentado até agora numa etapa inicial de uma metodologia projetual em arquitetura paisagística - a análise e compreensão de um problema de projeto - de acordo com o esquema a seguir (Figura 1):

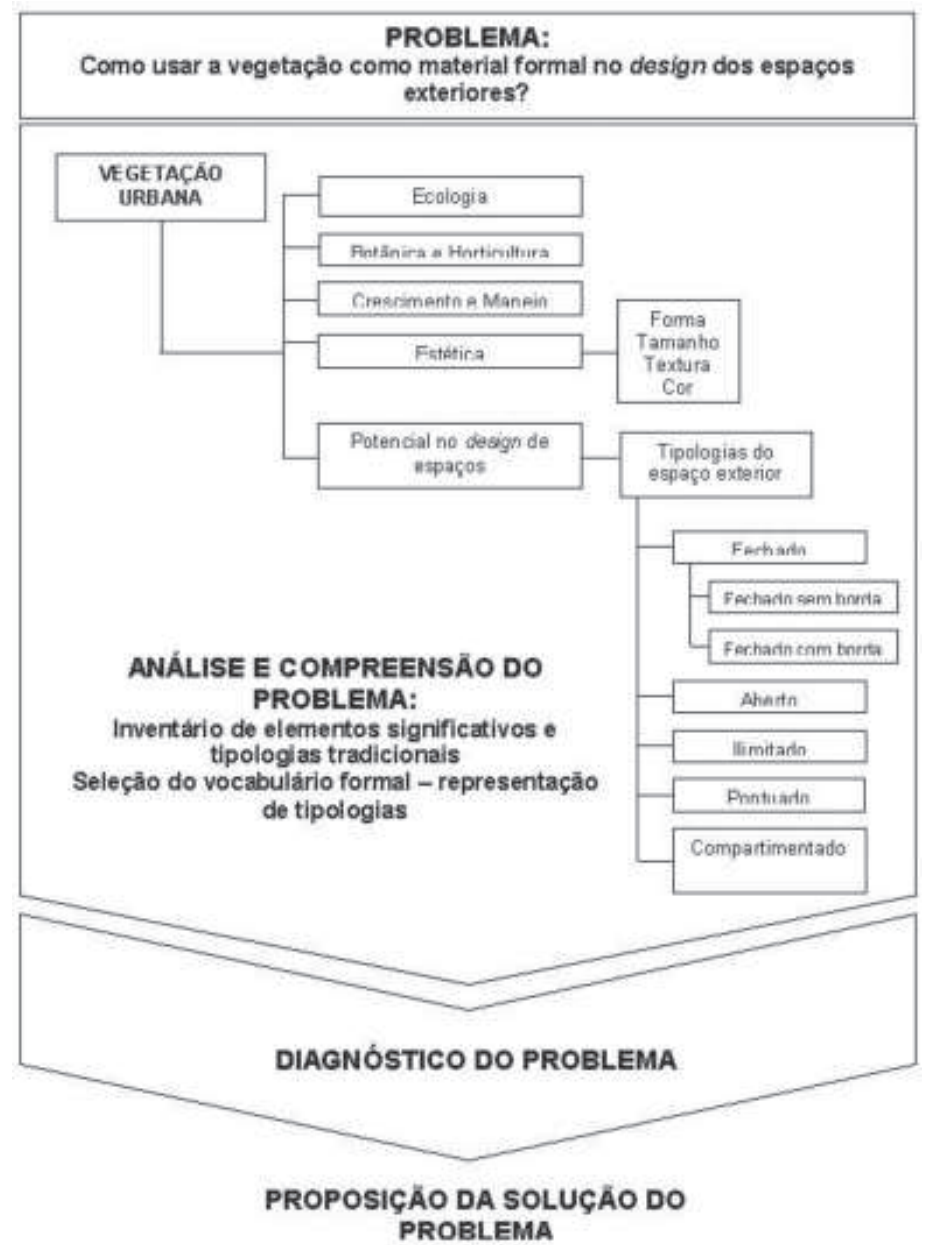

Figura 1: Esquema de uma metodologia projetual em arquitetura paisagística Fonte: Organizado pelo autor, 2003

A preocupação principal deste artigo é justamente contribuir para uma etapa inicial do processo projetual da Arquitetura Paisagística, servindo como estudo norteador de intervenções urbanas. Isto justifica a necessidade de localizar a atividade da Arquitetura Paisagística como disciplina projetual e destacar a importância de uma metodologia de projeto para espaços exteriores.

Com o objetivo de verificar como a vegetação inserida nos espaços livres urbanos do sistema viário constitui um elemento de desenho urbano, é interessante que se apresente uma sistematização da análise do problema de projeto aprofundando os estudos sobre a configuração das tipologias dos espaços exteriores relacionando-os com as vias urbanas. Para tanto, é de fundamental importância entender o plantio das espécies vegetais (que pode se dar de forma linear ou livre), e o fechamento proporcionado pela vegetação (relacionado ao plano verti- 
cal, da base ou do teto). Agregando estes dois conceitos ao esquema da Figura 1, podemos confeccionar um novo esquema (Figura 2) que reordene a metodologia projetual apontada e indique elementos para uma sistematização da análise do problema de projeto. Enquanto no primeiro esquema (Figura 1) enfatizava-se uma primeira aproximação relacionada à análise e compreensão do problema projetual; agora no novo esquema (Figura 2) a atenção é dada a uma segunda aproximação à mesma questão, destacando-se o potencial de design que a vegetação tem ao ser inserida no sistema viário.

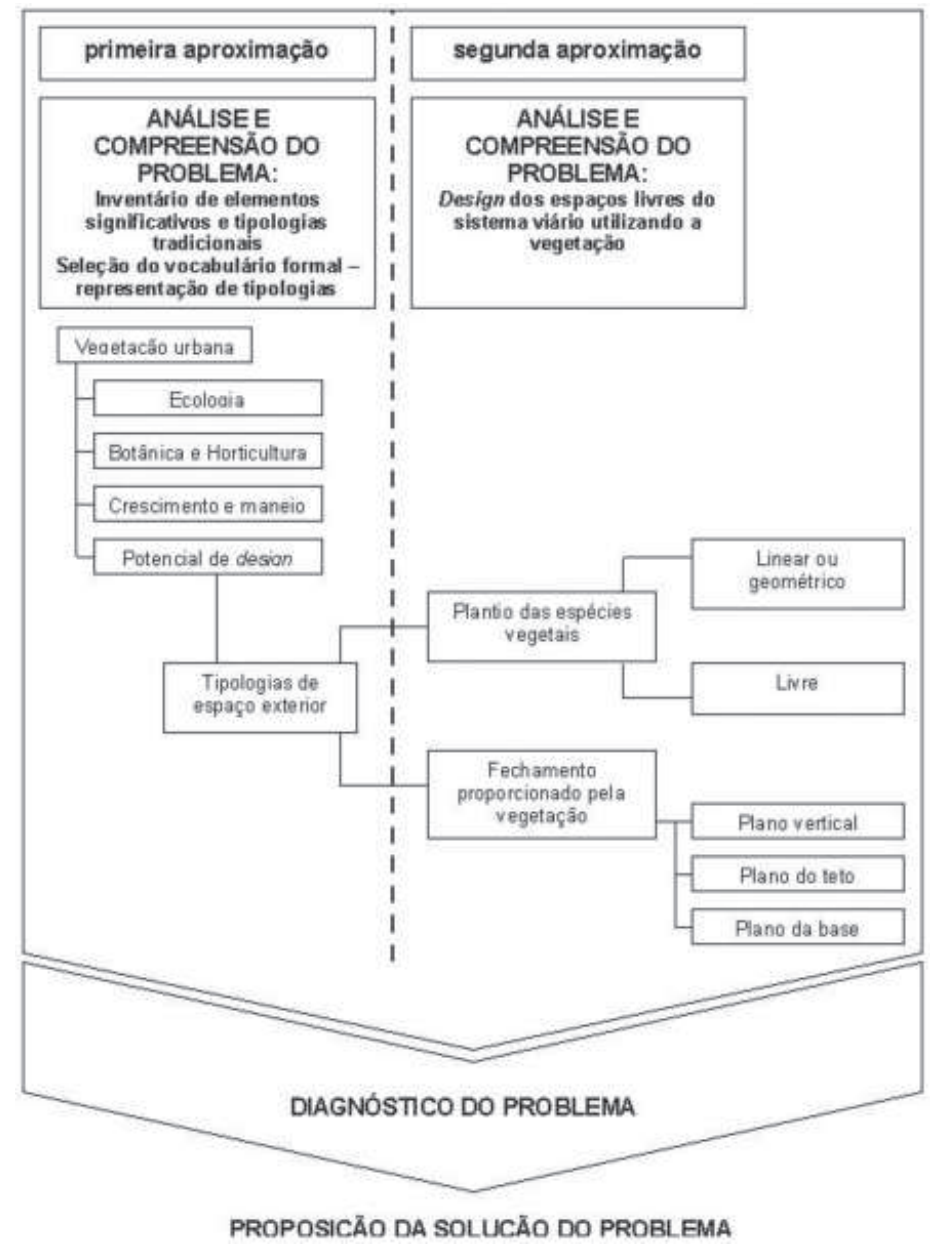

Figura 2: Esquema de uma metodologia projetual em arquitetura paisagística: duas aproximações na análise e compreensão do problema

Fonte: Organizado pelo autor, 2003

\section{Pesquisa de campo: Análise e compreensão da vegetação inserida nos espa- ços livres urbanos do sistema viário da área central de Florianópolis}

O objetivo desta pesquisa de campo é exemplificar a etapa de sistematização da análise do problema de projeto, a qual foi desenvolvida e apresentada neste artigo. Para tanto, foi realizado um estudo em uma área localizada no município de Florianópolis, capital do estado de Santa Catarina, região sul do Brasil. Florianópolis possui uma área de $436,5 \mathrm{~km}^{2}$ e no ano de 2000 tinha 341.781 habitantes, cerca de 6\% do total de habitantes de SC (IBGE, 2003). O município é formado pela Ilha de Santa Catarina e uma porção continental, sendo que o centro urbano localiza-se na ilha e possui uma área de $5,9 \mathrm{~km}^{2}$.

A área delimitada para o estudo é designada pelo Instituto de Planejamento Urbano de Florianópolis (IPUF) como parte do Distrito Sede, e deste apenas um único bairro será alvo da análise. Para a elaboração do estudo proposto, delimitou-se a Área Central da cidade. 


\section{Metodologia da pesquisa de campo}

Como metodologia geral desta pesquisa de campo, buscou-se elencar ruas e avenidas expressivas no tocante à vegetação urbana (Figura 3). Com oito ruas e avenidas escolhidas, partiu-se para um registro fotográfico de cada uma delas. Este registro foi realizado nos meses de janeiro e fevereiro de 2003 e objetivou-se o levantamento de imagens das vias enfatizando a localização e configuração dos espaços livres do sistema viário.

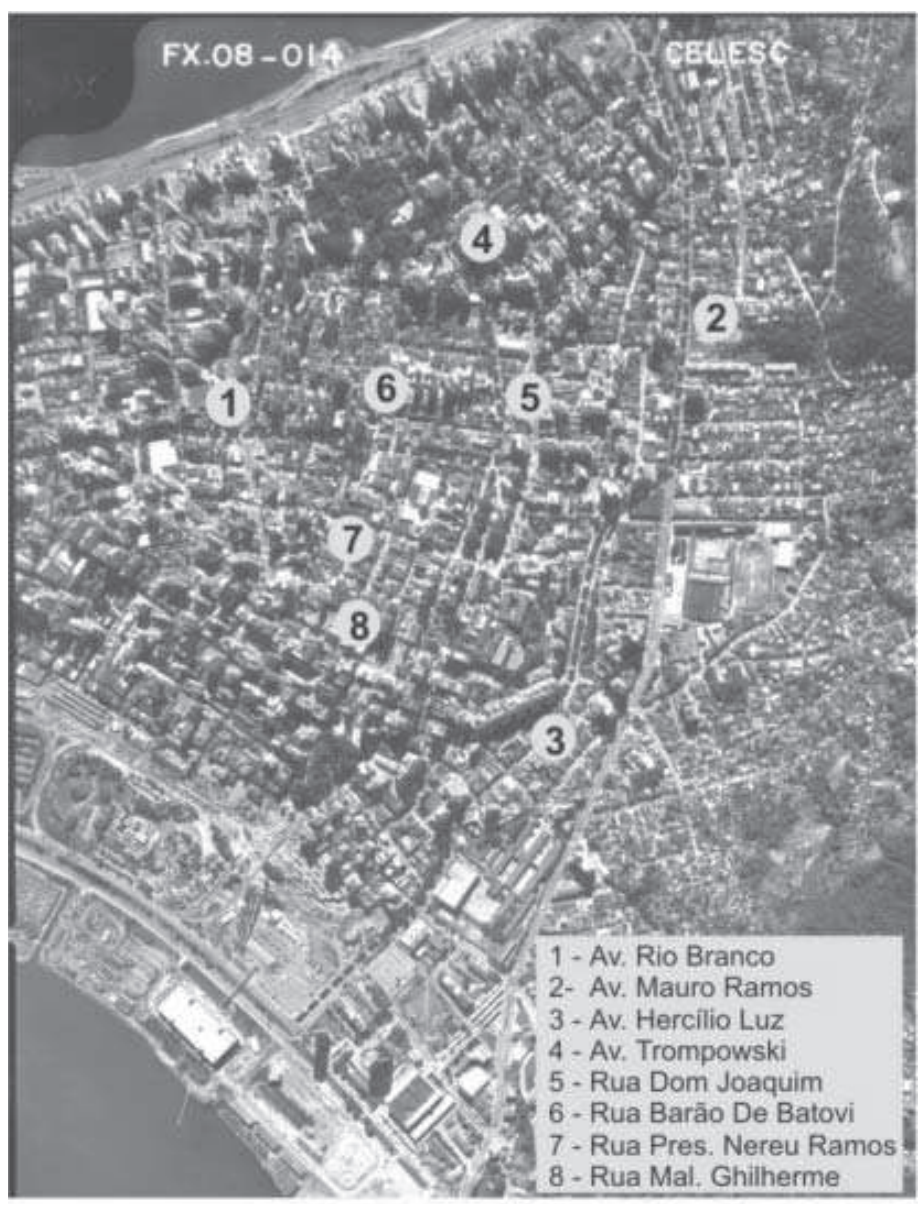

Figura 3: Rua e avenidas a serem estudadas

Fonte: Base cartográfica Aerofoto 1998 CELESC (INFOARQ, 2003)

Após concluído o registro fotográfico, separaram-se as imagens de cada via e iniciou-se uma sistematização da análise do problema da vegetação inserida nos espaços livres do sistema viário (neste caso cada rua ou avenida) usando-se as próprias fotografias. Estas imagens foram avaliadas da seguinte forma:

1. Primeira aproximação: inventário dos elementos significativos e tipologias tradicionais: Potencial no design dos espaços: verificação das tipologias de espaço exterior encontradas na rua ou avenida.

2. Segunda aproximação: design dos espaços livres do sistema viário utilizando a vegetação: Aprofundamento no estudo da tipologia de espaço exterior: (1) verificação da forma de plantio das espécies vegetais e (2) verificação do fechamento proporcionado pela vegetação.

A leitura das fotografias foi organizada através de uma ficha de dados (Figura 4) para cada rua ou avenida analisada, para posteriormente os dados levantados serem interpretados em direção a conclusões e recomendações. A ficha de dados foi confeccionada tomando-se como partido dois momentos distintos: o da primeira aproximação e o da segunda aproximação. 
Com isto, a sistematização da análise do problema da vegetação inserida no sistema viário foi estruturada de uma maneira concisa e prática. Na primeira parte da ficha, a qual tratava da primeira aproximação, foram elencadas as tipologias de espaço exterior (fechado com borda, fechado sem borda, aberto, ilimitado, pontuado e compartimentado) em uma tabela com duas colunas onde se assinalava a presença ou não de tais tipologias. Para tanto, além de consultar todas as fotografias de cada rua, o próprio ato do registro fotográfico in loco contribuiu para o preenchimento desta etapa da análise. Neste momento, com os conceitos de cada tipologia bem claros e definidos, foram estudadas as presenças de cada tipologia de espaço exteriores registrando sua existência (coluna sim ou não da tabela). Cabe ressaltar que somente a tipologia mais expressiva foi levada em consideração nesta etapa de análise. Desta forma, a tipologia de espaço exterior a que se refere cada rua é aquela mais marcante em toda sua extensão.

Na segunda parte da ficha de dados, foram organizados os conceitos referentes à segunda aproximação. Confeccionaram-se duas tabelas, sendo que a primeira tratava da forma de plantio e a segunda do fechamento proporcionado pela vegetação. Em relação à forma de plantio, a análise foi realizada de forma simples, onde se verificava se o plantio era linear ou livre e se este se dava nos dois lados da via, no canteiro central ou em um lado da via. Para a anotação destas constatações, listaram-se as duas formas de plantio e assinalava-se a maneira como se expressava este plantio (dois lados da via, canteiro central, um lado da via). Para o fechamento proporcionado pela vegetação, os dados foram sistematizados através de uma escala de valores. O fechamento de cada plano (vertical, da base e do teto) vinha acompanhado de uma escala de 1 a 5 em três situações diferentes (pouco, médio e muito). Nesta escala de 1 a 5, 1 significava a expressão mínima da situação e 5 a expressão máxima, sendo os demais números da escala $(2,3$ e 4$)$ expressões intermediárias e gradativas entre a expressão mínima e a máxima da situação. Semelhante ao que foi realizado na primeira aproximação, foi analisada a via em toda sua extensão e assinalou-se com base nesta escala o fechamento que a vegetação proporcionava, na escala do pedestre, nos planos vertical, da base e do teto.

A ficha de dados foi um instrumento de grande utilidade para a organização das informações coletadas no levantamento de campo e no registro fotográfico. Com estes dados organizados partiu-se para sua melhor compreensão objetivando traçar conclusões e recomendações acerca do problema de pesquisa.

\section{Considerações finais}

A análise da inserção da vegetação urbana nos espaços livres do sistema viário da área de estudo pode ser resumida da seguinte maneira:

- plantio linear configurando uma tipologia de espaço exterior pontuada, e

- esta tipologia resulta em um fechamento mais expressivo do plano vertical conforme a modulação do espaço livre em maior ou menor grau, a qual é obtida pelo espaçamento na plantação das espécies vegetais.

Logo, constatamos pouca variação de tipologias de espaço exterior o que traz pouca diversidade à arquitetura da paisagem da cidade, uma vez que as imagens urbanas repetem-se de uma rua para a outra. Isto também influencia na legibilidade da cidade e na construção de referenciais urbanos.

254 Também se verificou que a vegetação urbana nesta área é sub-aproveitada, pois o fechamento dos planos é proporcionado apenas pela modulação dos troncos das espécies arbóreas. $\bigcirc$ fechamento sendo "refém" da modulação reflete situações como clareiras no plano vertical muitas vezes desnecessárias ou mal posicionadas, isto é, não coincidindo com desvios ou re- 
tornos na via.

\section{ANÁLISE E COMPREENSÃO: vegetação inserida no sistema viário}

Avenida/Rua:

\section{PRIMEIRA APROXIMAÇÃO}

\begin{tabular}{|l|l|l|}
\hline TIPOLOGIA DE ESPAÇO EXTERIOR & SIM & NĀO \\
\hline Fechado com borda & & \\
\hline Fechado sem borda & & \\
\hline Aberto & & \\
\hline llimitado & & \\
\hline Pontuado & & \\
\hline Compartimentado & & \\
\hline
\end{tabular}

\section{SEGUNDA APROXIMAÇÃO}

FORMA DE PLANTIO

\begin{tabular}{|l|l|l|l|}
\hline PLANTIO & DOIS LADOS DA VIA & CANTEIRO CENTRAL & UM LADO DA VIA \\
\hline Linear & & & \\
\hline Livre & & & \\
\hline
\end{tabular}

FECHAMENTO PROPORCIONADO PELA VEGETAÇÃO

\begin{tabular}{|c|c|c|c|c|c|c|c|c|c|c|c|c|c|}
\hline \multirow{2}{*}{ FECHAMENTO } & \multicolumn{4}{|c|}{ POUCO } & \multicolumn{4}{|c|}{ MÉDIO } & \multicolumn{5}{|c|}{ MUITO } \\
\hline & 1 & 2 & $\begin{array}{ll}34 \\
4\end{array}$ & 5 & 1 & 2 & & 45 & 1 & 2 & & & 5 \\
\hline Plano & & & & & & & & & & & & & \\
\hline Plano da base & & & & & & & & & & & & & \\
\hline Plano do teto & & & & & & & & & & & & & \\
\hline
\end{tabular}

Figura 4: Ficha de avaliação

Fonte: Organizado pelo autor, 2003

Constatou-se o destaque de duas avenidas no que se refere à vegetação urbana: as Avenidas Trompowski (Figura 5) e Hercílio Luz (Figura 6). Em ambas, temos uma quantidade significativa de espécies vegetais configurando bons espaços livres. Mesmo tendo destaque, estas avenidas seguem a mesma linha das outras analisadas, possuindo um forte plantio linear, e diferindo apenas a tipologia de espaço exterior da Avenida Trompowski, a qual é fechada sem borda.

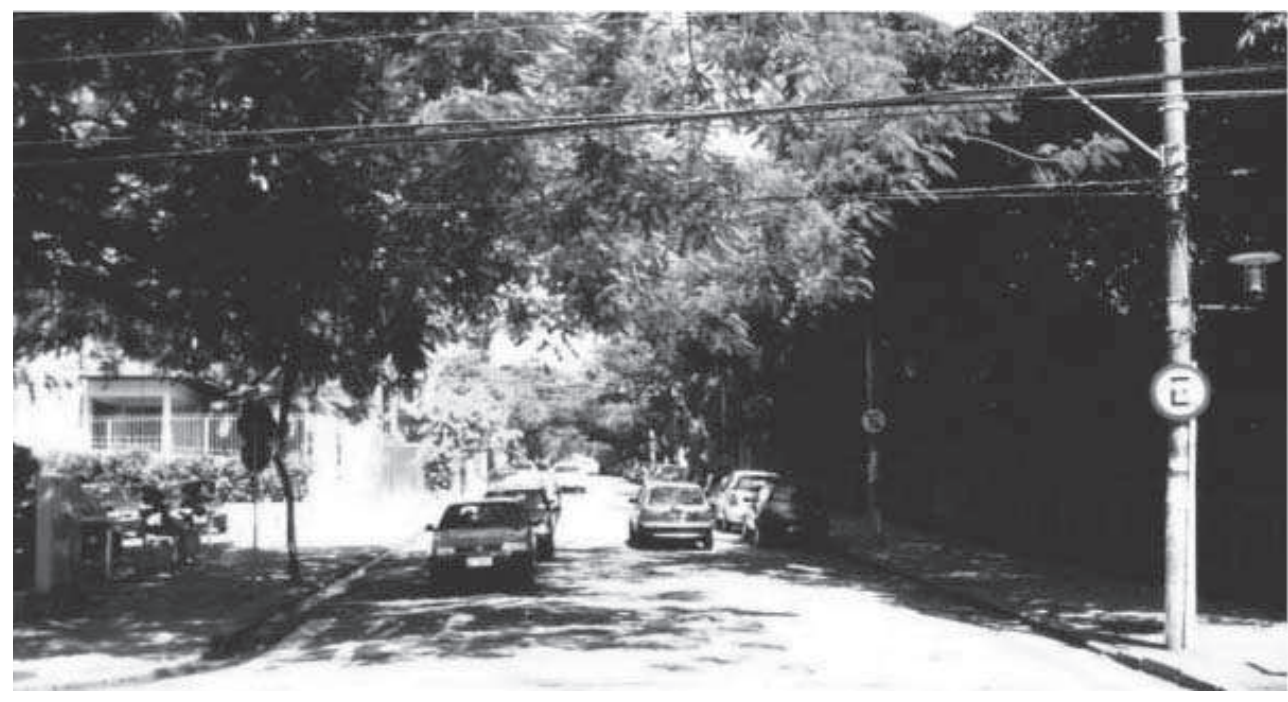

Figura 5: Avenida Trompowski

Fonte: Autor, 2003 


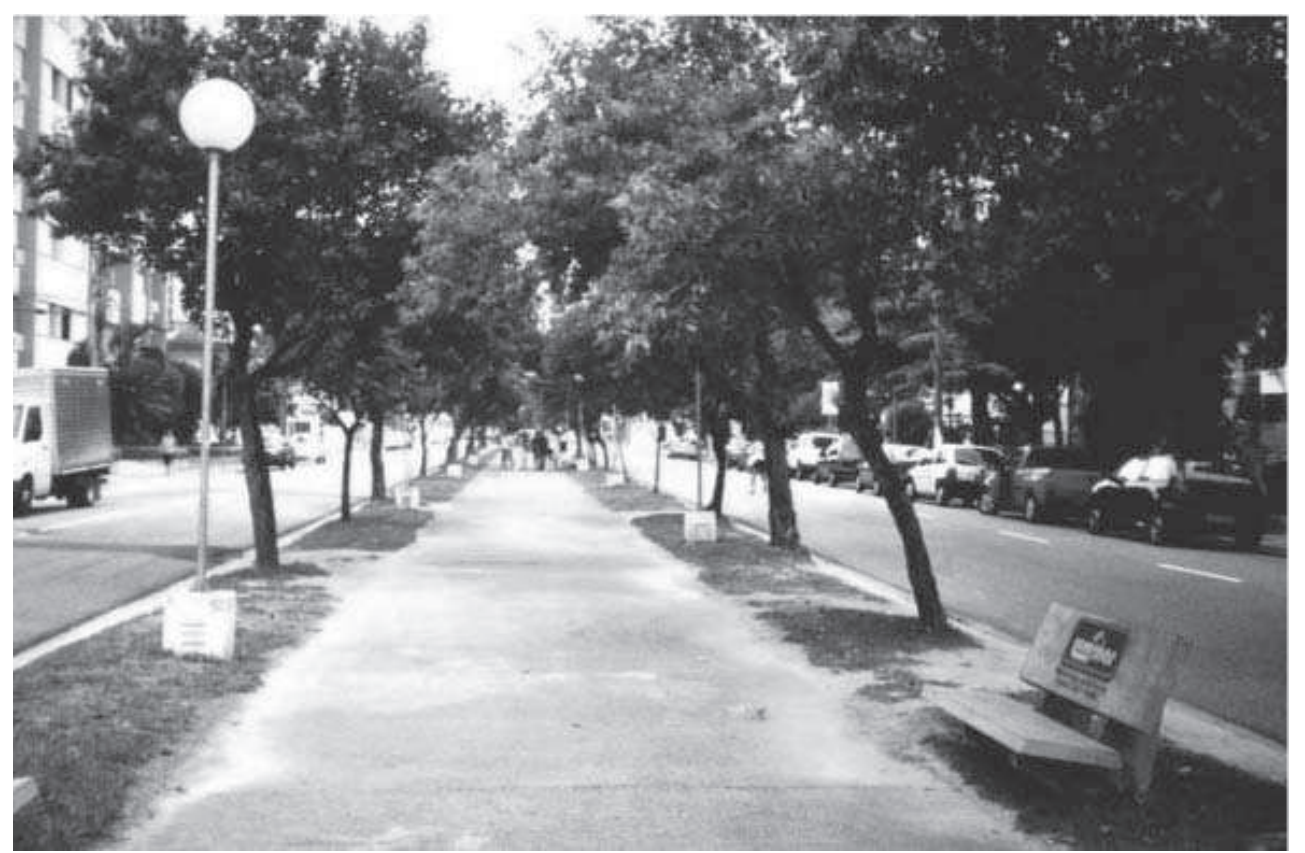

Figura 6: Avenida Hercílio Luz Fonte: Autor, 2003

Finalmente, com esta pesquisa de campo pôde-se exemplificar o uso da sistematização da análise do problema de projeto. Através desta proposta metodológica de análise podemos embasar de maneira segura o ato projetual por meio de uma sistematização de conceitos. A pesquisa de campo serviu para demonstrar como sistematizar uma análise organizando de forma concatenada os aspectos conceituais de determinada temática. O resultado desta análise deve ser enquadrado como dados a serem considerados no ato projetual, incorporando os êxitos de determinados casos e evitando os fracassos de outros. A sistematização da análise do problema projetual não é uma ferramenta de projeto, mas sim uma maneira de se compreender melhor o problema projetual. Somente após esta compreensão, serão traçados os diagnósticos para posteriormente propor a(s) solução(ões) do problema.

\section{Bibliografia}

DALCIN, Eduardo; MILANO, Miguel. Arborização de vias públicas. Rio de Janeiro: Light, 2000.

FRANCO, Maria de Assunção Ribeiro. Desenho ambiental: Uma introdução à arquitetura da paisagem como paradigma ecológico. São Paulo: Annablume/Fapesp, 1997.

GREY, Gene W.; DENEKE, Frederick J. Urban forestry. EUA: John Wiley \& Sons, 1978.

HOUGH, Michael. Naturaleza y ciudad. Barcelona: Gustavo Gilli, 1998.

IBGE. Instituto Brasileiro de Geografia e Estatística. Disponível em: <http://www.ibge.gov.br>. Acesso em: 02 fev. 2003.

INFOARQ. Grupo de Pesquisa da Informática na Arquitetura/Departamento de Arquitetura e Urbanismo/Centro Tecnológico/Universidade Federal de Santa Catarina. Floripa digital. Disponível em: <http://www.arq.ufsc.br/infoarq>. Acesso em: 21 mar. 2003.

LAURIE, Michael. An introduction to landscape architecture. Nova Jersey: Prentice Hall, 1986.

MACEDO, Silvio Soares. Espaços livres. Paisagem e Ambiente: Ensaios, São Paulo, n. 7, p. 15-56, 1995.

MACHARG, lan L. Design with nature. Nova York: John Wiley \& Sons Inc., 1969. 
MAGALHÃES, Manuela Raposo. A arquitectura paisagista: Morfologia e complexidade. Lisboa: Editorial Estampa, 2001.

SANTOS, Rodrigo Gonçalves dos. Arquitetura da paisagem da cidade: Uma leitura da vegetação urbana inserida no sistema viário. 2003. Dissertação (Mestrado em Engenharia de Produção) - Universidade de Santa Catarina - UFSC, 2003.

SPIRN, Anne Whiston. O jardim de granito: A natureza no desenho da cidade. São Paulo: Edusp, 1995. 
